\title{
Compact 810 kA linear transformer driver cavity
}

\author{
J. R. Woodworth, ${ }^{*}$ W. E. Fowler, B. S. Stoltzfus, W. A. Stygar, M. E. Sceiford, and M. G. Mazarakis \\ Department 1671, Sandia National Laboratories, Albuquerque, New Mexico 87185, USA
}

H. D. Anderson and M. J. Harden

National Security Technologies, Albuquerque, New Mexico 87123, USA

J. R. Blickem

Ktech Corporation, Albuquerque, New Mexico 87123, USA

R. White

L3 Communications, Pulse Sciences Division, San Diego, California 92111, USA

\section{A. A. Kim}

High Current Electronics Institute, Tomsk, Russia

(Received 27 January 2011; published 14 April 2011; publisher error corrected 19 April 2011)

We are performing experiments with a 92-kV, 810-kA, 74.6-GW linear transformer driver (LTD) cavity. This cavity generates a $\sim 100$ ns power pulse from DC-charged capacitors in a single step. Our experiments start with an existing 100-kV, 490-kA LTD cavity and are making a number of improvements to it that are aimed at increasing the cavity's peak output power and better understanding its operation. We are making improvements to the gas switches, the capacitors, and the magnetic toroids as well as heavily instrumenting the cavity. These experiments have increased the cavity's output current into a matched load by $65 \%$ without increasing its volume.

DOI: 10.1103/PhysRevSTAB.14.040401

PACS numbers: $84.30 . \mathrm{Ng}, 84.70 .+\mathrm{p}$

\section{INTRODUCTION}

Linear transformer drivers (LTDs) are a new pulsedpower architecture that may dramatically reduce the cost and size of future pulsed-power accelerators. In LTDs, DCcharged capacitors are discharged in parallel to provide a $\sim 100$-ns wide power pulse to a load in one step, without any of the pulse compression hardware used in traditional pulsed-power accelerators [1-9]. We are testing a number of changes to the existing LTD-II [7] cavity to increase its peak power. We are also adding diagnostics to the cavity to allow us to better understand its operation. We are calling the new cavity LTD-III.

In our first set of experiments, we replaced the baseline Russian gas switches with improved low-inductance switches and have also used an improved capacitor design developed specifically for LTD's. Both of these changes have decreased the system inductance and increased the peak output power. In the second set of experiments we replaced the silicon-steel magnetic toroids in the cavity with lower loss Metglas ${ }^{\circledR}$ toroids, which lowered the eddycurrent losses in the cores and also increased the cavity's

\footnotetext{
*jrwoodw@sandia.gov
}

Published by the American Physical Society under the terms of the Creative Commons Attribution 3.0 License. Further distribution of this work must maintain attribution to the author(s) and the published article's title, journal citation, and DOI. output power. Since the new switches and capacitors were significantly smaller than the ones used in the original cavity, we performed a third experiment with $45 \%$ larger capacitors in the cavity, which again increased the output power and slightly lengthened the pulse.

Figure 1 shows a schematic of a basic linear transformer driver "brick" that consists of two capacitors charged to opposite polarity, a triggered switch and a set of magnetic toroids. When the switch is triggered, current attempts to flow around the outside of the LTD cavity, but is blocked by the magnetic toroids until the toroids saturate. This causes a fast-rising high-voltage pulse in the center of the

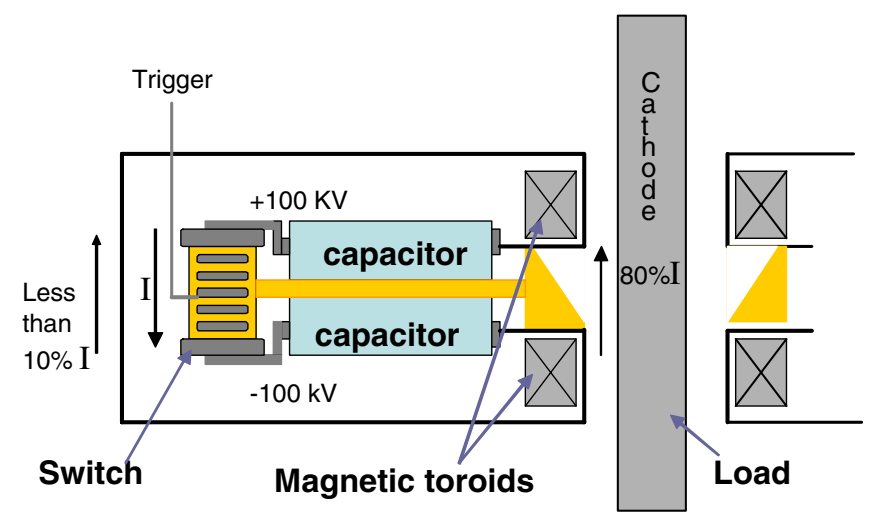

FIG. 1. Schematic of an LTD brick showing DC-charged capacitors, a triggered switch, and magnetic toroids. 
LTD cavity that may be coupled to a variety of loads, including a coaxial transmission line with a cathode stalk on the center line as shown in Fig. 1.

\section{APPARATUS}

\section{A. Capacitors and switches}

Figure 2 compares the baseline gas switch designed by the High Current Electronics Institute (HCEI) at Tomsk, Russia [10] with the switch jointly designed by L3 pulse sciences and Sandia Laboratories [11,12] and used in LTDIII. The L3-Sandia switch is significantly smaller than the HCEI switch and, hence, adds less inductance to the brick circuit. The L3-Sandia switch is a two-stage switch with midplane triggering and a UV preionization gap in the midplane to lower the switch's command jitter. The L3-Sandia switch has two each $6.4 \mathrm{~mm}$ electrode gaps and is insulated with dry air at a pressure of 158 psi (absolute). Figure 3 compares the single-ended general

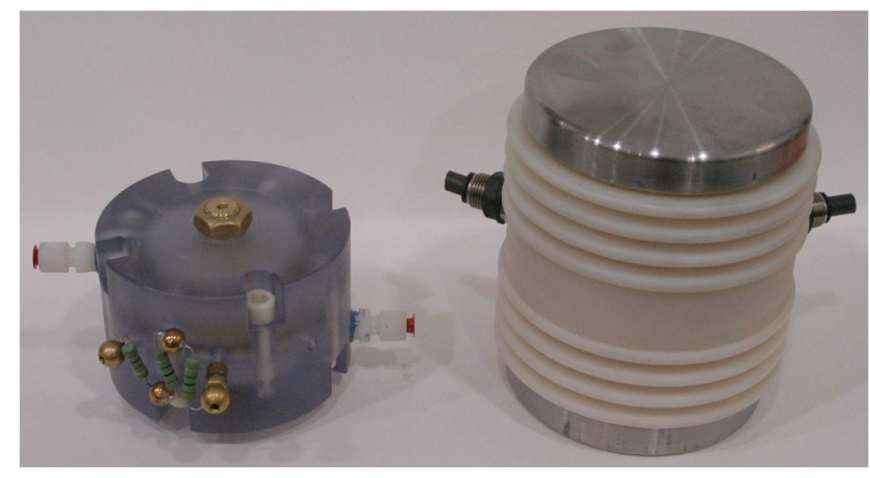

FIG. 2. Comparison of the 7.6-cm-tall L3-Sandia switch (left) used in the LTD-III experiments with the $15-\mathrm{cm}$-tall baseline switch (right) developed by the High Current Electronics Institute in Tomsk, Russia.

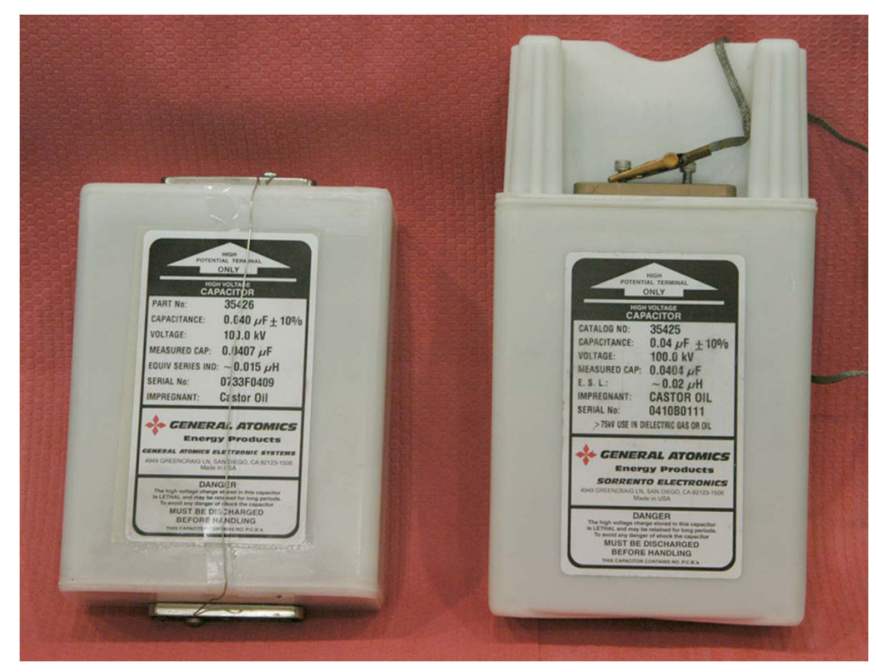

FIG. 3. Comparison of the double-ended 40-nF capacitors used in LTD-III with the single-ended 40-nF capacitors used in previous experiments. atomics 40-nF capacitors used in LTD-II with the 40-nF double-ended capacitors used in LTD-III. The doubleended capacitors allow the brick circuitry to be packed more tightly, also resulting in a lower system inductance.

\section{B. Magnetic toroids}

Two sets of ferromagnetic toroidal cores were used in our experiments. Both types of cores were fabricated of a continuous winding of iron alloy with Mylar or polyethylene between adjacent windings to prevent shorting from turn to turn. The cores had inner diameters of $86.4 \mathrm{~cm}$ and were approximately $5.1-\mathrm{cm}$ thick [13].

In the first experiments, we used the silicon-steel cores supplied with LTD-II. These cores were produced by researchers at the High-Current Electronics Institute in Tomsk, Russia, and were fabricated of ET3425 transformer iron $[6,14]$. The metal tapes used for the windings in the ET3425 cores were 80 -microns thick and $18 \mathrm{~mm}$ tall with 12-micron thick layers of Mylar between metal turns. ET3425 has a saturation flux intensity of $\sim 2.0$ Tesla. The cavity contained six of the ET3425 cores, which had for a total Volt-second product from $-\mathrm{B}$ saturation to $+\mathrm{B}$ saturation of approximately $22 \mathrm{mV}$-seconds.

For the second two experiments, we used toroidal cores of $2605 \mathrm{CO}$ metallic glass that were supplied by Metglas ${ }^{\circledR}$, Inc. [15]. The metal tapes used for the windings of the Metglas ${ }^{\circledR}$ cores were 23 -microns thick and $3.56-\mathrm{cm}$ tall. Four-micron-thick layers of polyethylene were wound between adjacent layers of Metglas ${ }^{\circledR}$. The Metglas ${ }^{\circledR}$ in each of the four cores had a cross-sectional area of $15.5 \mathrm{~cm}^{2}[6,8] .2605 \mathrm{CO}$ has a saturation intensity of 1.7 Tesla. The cavity contained four of the Metglas ${ }^{\circledR}$ cores, which had a total volt-second product of approximately $18 \mathrm{mV}$-seconds. We expected the $23-\mu \mathrm{m}$-thick Metglas ${ }^{\circledR}$ cores to have much lower losses than the $80 \mu \mathrm{m}$-thick ET3425 cores since the losses in the cores are inversely proportional to the square of the winding thickness.

The magnetic domains in the cores were "set" just before each LTD-III shot by discharging a unipolar current pulse around the metal exterior casing of the LTD-III cavity in the opposite polarity to the main high-voltage pulse generated by the LTD. This "premagnetization pulse" had a peak current of $2 \mathrm{kA}$ and a full width at half maximum of 140 microseconds.

\section{LTD-III cavity}

Figure 4 shows a picture of the LTD-III cavity. Twenty bricks consisting of $40-\mathrm{nF}$ or $58-\mathrm{nF}$ capacitors and L3-Sandia switches [11] surround magnetic toroids and an annular liquid resistive load cavity. During normal operation, the top capacitors are charged to positive voltage and the bottom capacitors are charged to negative voltage. The overall cavity diameter is $199 \mathrm{~cm}$. The outer diameter of the annular resistive load is $77 \mathrm{~cm}$. 


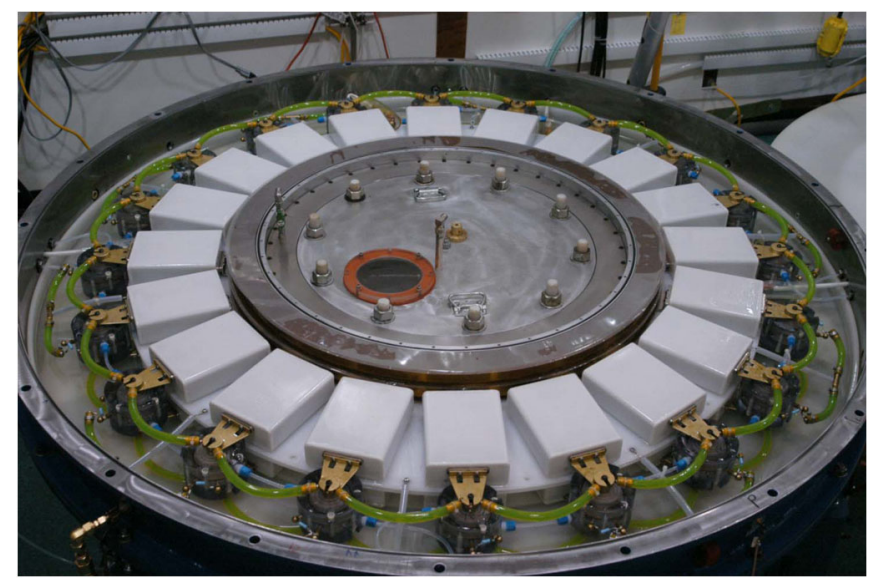

FIG. 4. Overview of the LTD-III cavity with 20 pairs of 40-nF capacitors, 20 switches and liquid charge and trigger resistors.

The cavity was filled with Luminol [16] transformer oil during operation. The oil was filled and drained through filters that removed particles and moisture. Most LTD cavities are used in a vertical orientation and a small $(\sim 2$ psi) negative pressure is applied to the top of the cavity to draw off any air bubbles in the cavity. Since our cavity was used in a horizontal position, debubbling the cavity was more challenging. We took several steps to remove air bubbles from the cavity once it was filled and the cover was in place. A $\sim 10$ liter transparent tank that was half-filled with oil was connected to the top of our cavity and we applied a $\sim 2$ psi negative pressure to this tank to draw bubbles out of the cavity. We also tilted the cavity $2^{\circ}$ from horizontal and recirculated oil from the bottom of the transparent tank back through the cavity to further flush out any remaining bubbles.

Figure 5 shows a cross section of the LTD-III cavity. Locations of the capacitors, switches, and resistive load cavity are indicated. The locations of ten load current B-dot detectors are indicated in a small cavity immediately

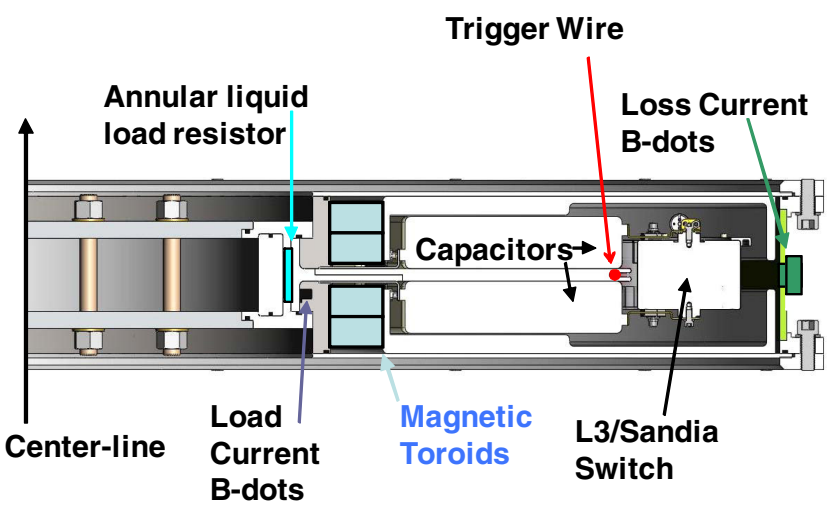

FIG. 5. Cross section of LTD-III cavity with 58-nF capacitors, showing location of capacitors, switches, magnetic toroids, and annular $\mathrm{KBr}$ resistive load along with load and loss current B-dot monitors. outside the resistive load. Loss current B-dots are located on the outer diameter of the cavity. The load current B-dots were calibrated while mounted in the LTD cavity hardware in the calibration laboratory for the $Z$ facility. The loss current B-dots were calibrated in separate fixtures in the same calibration laboratory. Figure 6 shows details of connections between the switches and capacitors in the initial experiments with $40 \mathrm{nF}$ capacitors and solid-state resistors. Figure 7 shows similar details of the connections in the final experiments using 58-nF capacitors and allliquid resistors. The charging resistors are $1-\mathrm{k} \Omega$ each and the trigger resistors are $500-\Omega$ each.

Three types of resistors were used in these experiments: Small $0.63-\mathrm{cm}$ diameter $500-\Omega$ liquid resistors initially used as trigger resistors and $1-\mathrm{k} \Omega$ solid-state resistors initially used as charge resistors. (Fig. 6) 1.9-cm diameter style of liquid resistors were eventually used for both $500-\Omega$ charge resistors and $1-\mathrm{k} \Omega$ charge resistors (Fig. 7). The small diameter liquid resistors were replaced because they developed air bubbles too frequently. The solid-state resistors were replaced because they occasionally shattered. All of the liquid resistors were copper sulfate solutions in yellow, oil-resistant plastic tubing.

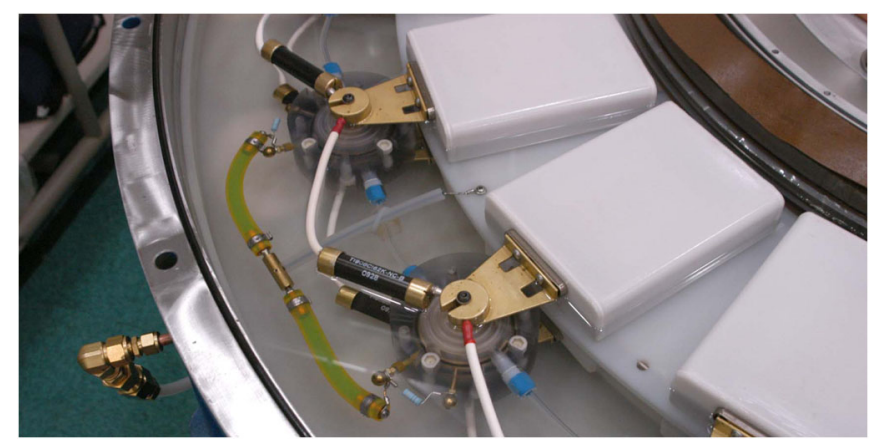

FIG. 6. Details of LTD-III connections with 40-nF capacitors, solid-state charge resistors, and liquid trigger resistors.

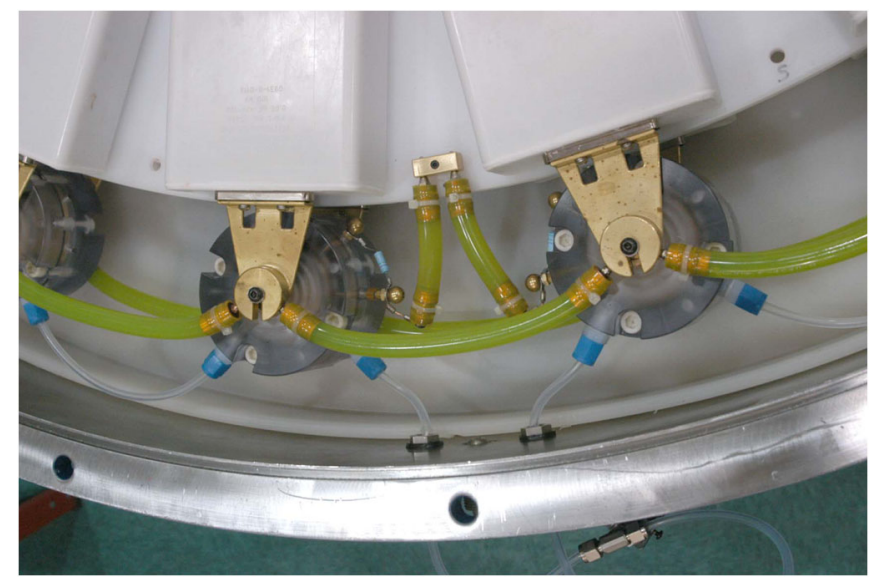

FIG. 7. Details of LTD-III connections with 58-nF capacitors, and all liquid charge and trigger resistors. 
In a simple resistor-inductor-capacitor (RLC) circuit, the maximum energy is transferred to the resistive load under matched-load conditions; i.e., when

$$
\mathrm{R}=(\mathrm{L} / \mathrm{C})^{0.5} .
$$

Under matched-load conditions in a simple RLC circuit, there is a $16 \%$ reversal of the current. In our experiments, we defined matched load as a $16 \%$ current reversal even though our circuit, which had magnetic toroidal cores in it, was not strictly a simple RLC circuit. Thus, our results are "near matched load."

Because LTD-III is a sealed cavity with high pressure gas switches inside it, mechanical rupture of a switch or a gas line could subject the cavity to the full switch gas pressure, which is more than the cavity is designed to withstand. We took two precautions to prevent the cavity from being overpressured in this manner. First, we put four pressure-relief valves [17] set for $1.5 \mathrm{psi}$ (gauge) on the outer diameter of the cavity. Hoses from these valves ran to a common dump tank. Second, since failures of the gas system are usually caused by an electrical arc inside the cavity that occurs during the charging of the cavity, we programmed the control system to abort the charge and lower the switch pressure to 2 psi in the event of a charge imbalance in the \pm charging system.

\section{Trigger system}

The trigger pulse for LTD-III was generated by discharging two 20-nF capacitors in parallel through a modified version of the HCEI switches described previously $[8,10]$. The trigger generator was outside the LTD-III cavity and the trigger pulse was conveyed to the cavity via two high-voltage $67-\Omega$ cables. The two cables entered the cavity $180^{\circ}$ apart from each other and attached to a wire located in a groove in the insulator plate separating the capacitors (see Fig. 5). This trigger pulse was then connected through twenty $500-\Omega$ resistors to each of the 20 switch midplanes.

\section{RESULTS}

Table I summarizes the results of our three experiments. Figure 8 shows currents through matched resistive loads during three different experiments. The peak current in the first experiment of $615 \mathrm{kA}$ is $\sim 25 \%$ higher than the $490 \mathrm{kA}$ peak currents achieved in LTD-II using HCEI switches and single-ended capacitors. This increase in peak current is due solely to the decrease in system inductance due to the improved capacitors and switches. In the second experiment, the Metglas ${ }^{\circledR}$ cores replaced the silicon-steel cores, reducing the losses and yielding a $650 \mathrm{kA}$ peak current for a $32 \%$ increase over LTD-II results. In the third experiment, 58- $\mathrm{nF}$ capacitors replaced the $40 \mathrm{nF}$ capacitors yielding a $810 \mathrm{kA}$ peak current with a $60 \mathrm{~ns} 10 \%$ to $90 \%$ rise time. While the use of $58 \mathrm{nF}$ capacitors increases the rise time of the pulse, the 100 ns zero-to-peak rise time we obtain with the $58 \mathrm{nF}$ capacitors is still a good match to 100 -ns wire-array implosion times on the $Z$ accelerator $[18,19]$.

Figure 9 shows the voltage and power waveforms for the tests with the $58 \mathrm{nF}$ capacitors and Metglas ${ }^{\circledR}$ toroids when the capacitors were charged to $\pm 100 \mathrm{kV}$ and discharged into a matched load. The peak load power was $74.6 \mathrm{GW}$.

Figure 10 shows the loss currents that leaked past the toroidal cores and traveled around the outside of the cavity. In the first experiment, the loss currents peaked at $59 \mathrm{kA}$ or about $9.6 \%$ of the load current. In the second experiment with the Metglas ${ }^{\circledR}$ cores, the loss currents peaked at about $15 \mathrm{kA}$ or $2.3 \%$ of the load current. In the experiment with the Metglas ${ }^{\circledR}$ cores and the $58 \mathrm{nF}$ capacitors, the loss current peaked at $51 \mathrm{kA}$ or $6.3 \%$ of the load current. In the experiments with the silicon-steel cores, the loss currents peaked about 20 ns later than the load current,

TABLE I. Summary of results for LTD-III shots into matched loads with capacitors charged to $\pm 100 \mathrm{kV}$.

\begin{tabular}{lccc}
\hline \hline Experiment & 1 & 2 & 3 \\
\hline Capacitors & $40 \mathrm{nF}$ & $40 \mathrm{nF}$ & $58 \mathrm{nF}$ \\
Toroidal cores & Silicon steel & Metglas® & Metglas ${ }^{\circledR}$ \\
Matched-load peak current $(\mathrm{kA})$ & 615 & 650 & 810 \\
Peak power $(\mathrm{GW})$ & 52 & 57 & 74.6 \\
Peak voltage $(\mathrm{kV})$ & 84.4 & 87 & 92 \\
$10 \%-90 \%$ rise time $(\mathrm{ns})$ & 48 & 50 & 60 \\
0-peak rise time $(\mathrm{ns})$ & 80 & 84 & 100 \\
Energy to load by peak of pulse $(\mathrm{J})$ & 2947 & 2951 & 4147 \\
Energy to load by 100 ns $(\mathrm{J})$ & 3769 & 3781 & 4147 \\
Energy to load by end of pulse $(\mathrm{J})$ & 5471 & 5742 & 9217 \\
Percent of capacitor bank energy to load by end of pulse & 68.4 & 71.8 & 79.5 \\
Volt-second product across load by end of pulse $(\mathrm{mV}-\mathrm{sec})$ & 11.5 & 11.5 & 14.25 \\
Load resistance from $V_{\text {load }} / I_{\text {load }}(\Omega)$ & 0.144 & 0.136 & 0.113 \\
Peak value of loss currents $(\mathrm{kA})$ & 59 & 15 & 51 \\
\hline \hline
\end{tabular}




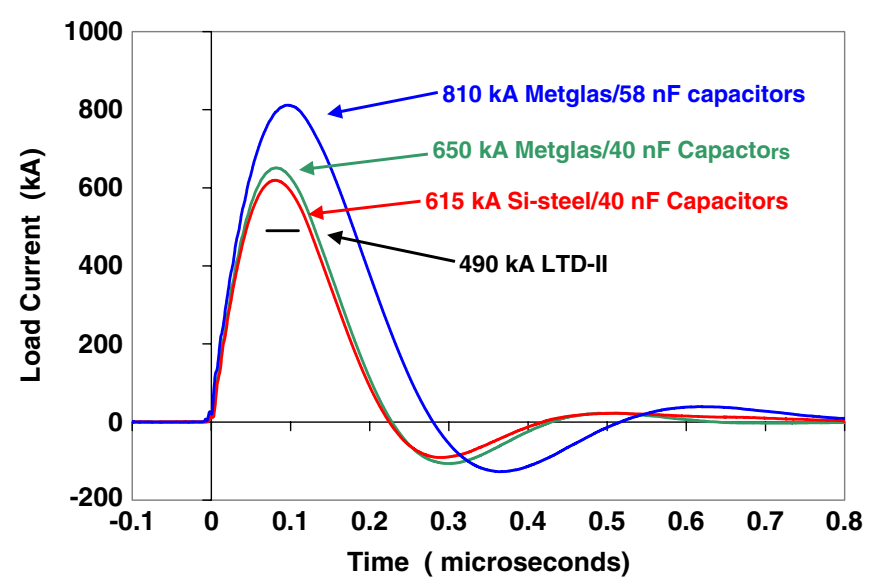

FIG. 8. LTD-III peak currents into matched loads with $40 \mathrm{nF}$ capacitors and Si-steel toroids (red), $40 \mathrm{nF}$ capacitors and Metglas ${ }^{\circledR}$ toroids (green), and $58 \mathrm{nF}$ capacitors and Metglas ${ }^{\circledR}$ toroids (blue). Peak LTD-II current levels are shown for comparison.

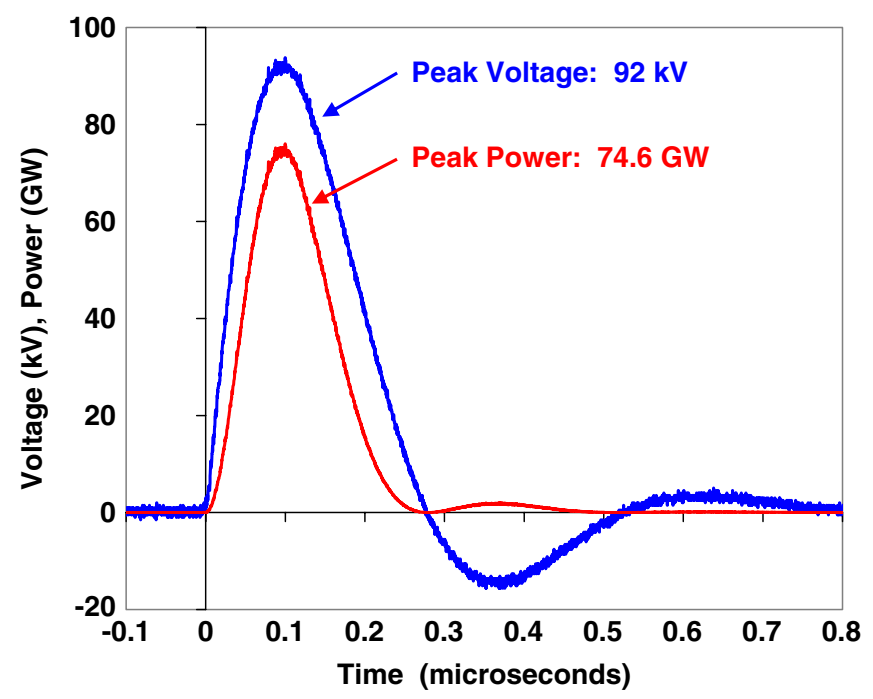

FIG. 9. Load voltage and power waveforms for LTD-III with $58 \mathrm{nF}$ capacitors and Metglas ${ }^{\circledR}$ toroids.

indicating that the effective impedance of the silicon-steel cores decreases with time during the pulse, in agreement with predictions by Kim et al. [20]. In contrast, the loss currents with the Metglas ${ }^{\circledR}$ cores peaked before the peak of the power pulse.

It is sometimes useful to refer to an effective "resistance" of the magnetic cores [8] defined simply as the load voltage divided by the loss current. With the silicon-steel cores, the effective core resistance at peak power was $1.5 \Omega$. With the Metglas ${ }^{\circledR}$ cores and $40 \mathrm{nF}$ capacitors, the effective resistance at peak power was $7.2 \Omega$. With the same Metglas ${ }^{\circledR}$ cores and $58 \mathrm{nF}$ capacitors, the effective resistance was $1.9 \mathrm{Ohms}$. All of these values are much larger than the $0.11-0.15-\Omega$ resistance of the flowing resistive load.

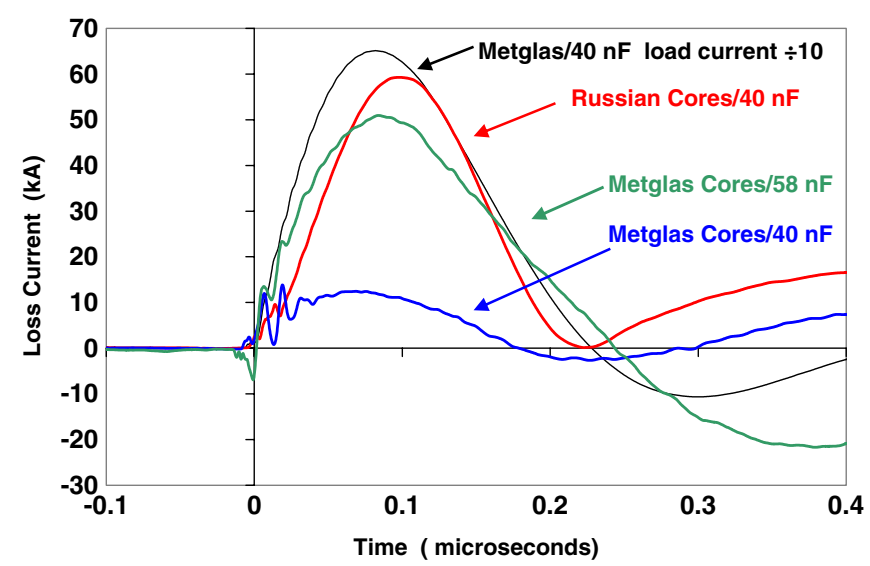

FIG. 10. Loss currents for the three experiments. A scaled current trace for one of the main current waveforms is shown for comparison.

In $\pm 100 \mathrm{kV}$ shots, the total volt-second product impressed across the magnetic cores for both tests with 40-nF capacitors was $11.5 \mathrm{mV}$-seconds, well below the $22 \mathrm{mV}$-second product of the silicon-steel cores or the $18 \mathrm{mV}$-second product of the Metglas ${ }^{\circledR}$ cores. The voltsecond product impressed across the Metglas ${ }^{\circledR}$ cores during the tests with $58 \mathrm{nF}$ capacitors was $14.25 \mathrm{mV}$, which was still lower than the $18 \mathrm{mV}$-second theoretically available. The dramatic increase in loss current in changing from 40- to 58-nF capacitors, however, suggests that we are nearing saturation of the Metglas ${ }^{\circledR}$ cores in the 58-nF shots.

Since we were interested in understanding the inductance of the LTD-III cavity, we took several low-voltage shots of LTD-III into a short-circuit load. To form a shortcircuit load, we drained the resistive load and then wrapped a thin brass foil around the entire circumference of the inner load insulator, providing a low-inductance short circuit between the top and bottom plates. Figure 11 shows

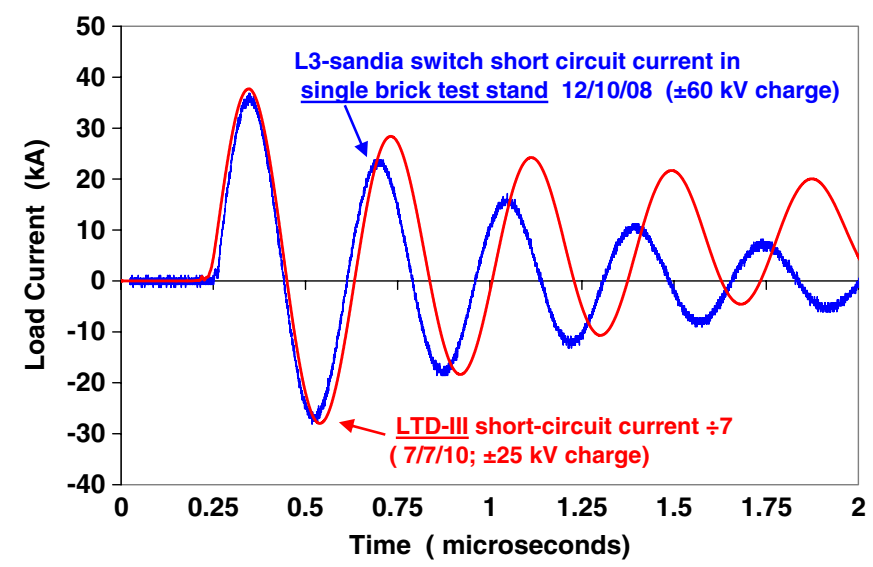

FIG. 11. Low-voltage, short-circuit currents in LTD-III compared with earlier data from our single brick test stand. Most of the increase in ringing period in LTD-III compared to the single brick test stand is caused by the thicker and longer spacer used to separate the capacitors on LTD-III. 


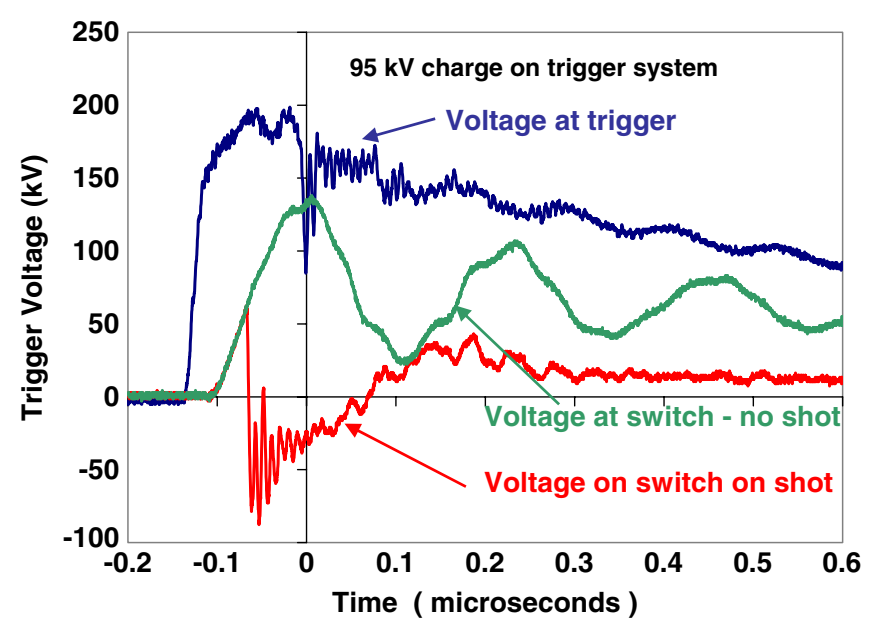

FIG. 12. Comparison of LTD-III trigger voltages measured at the trigger generator (blue), at a switch when no voltage was on the switch (green), and at a switch during an LTD-III shot (red).

the current into the short-circuit load with $40 \mathrm{nF}$ capacitors in LTD-III charged to $\pm 25 \mathrm{kV}$. For comparison, Fig. 11 also shows a short-circuit trace from our earlier experiments with a single LTD brick [11]. Based on the ringing period of 0.38 microseconds, we estimate the total inductance of the shorted cavity to be $9.1 \mathrm{nH}$. In our single LTD brick experiments, we measured an inductance per brick to $155 \mathrm{nH}$. Dividing this inductance by 20 to simulate the effect of 20 single bricks in parallel gives a simulated inductance of $7.75 \mathrm{nH}$ for the 20 bricks in parallel, which is significantly smaller than the $9.1 \mathrm{nH}$ that we measure for LTD-III.

Figure 12 shows voltage waveforms of the trigger pulse measured at the trigger generator and at a switch inside LTD-III. The measurement at the switch shows two conditions: first, when no charge voltage was applied across the switches, allowing the trigger pulse to ring and, second, during a normal shot of the cavity. The trigger pulse measured at the generator has a $10 \%-90 \%$ rise time of $\sim 20 \mathrm{~ns}$, but this trigger rise time has increased to $\sim 60 \mathrm{~ns}$ by the time the trigger actually reaches a switch. While the trigger pulse still has more than enough voltage to trigger the switches, this increase in rise time is likely to adversely affect the simultaneity of the triggering of the twenty switches as well as the overall cavity jitter.

\section{DISCUSSION}

In order to better understand the sources of inductance in the system, we assembled an "inductance budget" for the LTD-III cavity with 40 and $58 \mathrm{nF}$ capacitors and compared it to estimates from our previous single brick experiments. In our inductance budget, we used known component inductances and zeroth-order estimates of the inductances caused by the spacing of power feeds in the cavity [21]. The inductances of the capacitors were obtained from the manufacturer. The inductances of the switches are from our previous work [11]. Table II summarizes our simulated inductances and then compares them to experimental results from short-circuit shots. Our calculated inductances are 5\%-10\% lower than the experimental values from the short-circuit shots. The increased thickness $(1.4 \mathrm{~cm}$ vs $0.64 \mathrm{~cm})$ and length $(31.5 \mathrm{~cm}$ vs $19.7 \mathrm{~cm}$ ) of the spacer between the capacitors accounts for most of the difference in inductance between our single brick experiments and the LTD-III cavity. Note that even with our improved switches and capacitors, over half of the circuit inductance is still in the switch. $45 \mathrm{nH}$ of this inductance is caused by the switch arcs themselves and $40 \mathrm{nH}$ is caused by the inductance of the current loop from the top capacitor, through the switch and back to the bottom capacitor.

The flowing resistive load was made up of a concentrated solution of potassium bromide in water. Typical resistivities ranged from $6 \Omega$-cm to $8 \Omega$-cm. These concentrated alkaline solutions rapidly degraded conductivity measuring probes [22] unless the measurement was taken in less than 10 seconds and then the probe was rinsed in deionized water then vinegar and then stored in deionized water. Load resistances determined from measuring the resistivity and then calculating resistance based on the load geometry typically were about $15 \%$ higher than load resistance values obtained using Ohm's law with the load voltage and current traces.

Large pulsed power drivers with 100-1000 LTD cavities will need each cavity to operate for 1000 shots without

TABLE II. Inductance of components in LTD systems. All inductances are in nano-Henries.

\begin{tabular}{lccc}
\hline \hline Parameter for single brick & $\begin{array}{c}\text { Single LTD brick } \\
\text { experiments }\end{array}$ & $\begin{array}{c}\text { LTD-III with } 40 \mathrm{nF} \\
\text { capacitors }\end{array}$ & $\begin{array}{c}\text { LTD-III with 58 } \mathrm{nF} \\
\text { capacitors }\end{array}$ \\
\hline Switch loop & 40 & 40 & 40 \\
Switch arcs & 45 & 45 & 45 \\
Two capacitors in series & 30 & 30 & 30 \\
Spacer between capacitors & 9.6 & 30.4 & 36 \\
Load resistor & 22.6 & 20.6 & 20.6 \\
Total inductance per brick & 147 & 166 & 171.6 \\
Inductance of 20 bricks in parallel & 7.36 & 8.3 & 8.58 \\
Experimental value & 7.75 & 9.1 & Not measured \\
\hline \hline
\end{tabular}


maintenance [23]. In our proof-of-principle experiments with the LTD-III cavity, we have not demonstrated this level of reliability. There are several areas where more work needs to be done. First, replacing the liquid resistors used in LTD-III is a high priority since liquid resistors change their values over time whether or not they are used. Second, air bubbles in the oil were a constant problem in these experiments and led to our pumping on the oil and recirculating it. New cavity designs that carefully consider how all the oil bubbles can be removed from the system would be very helpful. Finally, it is not clear that we are using the best transformer oil for our experiments. While Luminol was chosen over Shell Diala-X because of its higher breakdown strengths in small areas under AC electric fields, more tests need to be done with larger areas and DC fields. More studies of the effects of dissolved air and water on the oil breakdown strengths would also be helpful.

\section{SUMMARY}

We have performed three experiments with an existing 490 kA LTD cavity to increase its peak current and better understand its operation. In the first experiment, we replaced the existing Russian switches and single-ended capacitors with improved L3-Sandia switches and double-end capacitors, significantly lowering the inductance of the cavity. This decrease in inductance raised the peak current to a matched load from 490 to $615 \mathrm{kA}$. In the second experiment, we replaced the existing silicon-steel magnetic cores with Metglas ${ }^{\circledR}$ cores, which lowered the core losses and increased the peak current to $650 \mathrm{kA}$. In the third experiment, we replaced the $40 \mathrm{nF}$ capacitors with $58 \mathrm{nF}$ capacitors, raising the peak current to a matched load to $811 \mathrm{kA}$. These experiments may lead to improved pulsed-power accelerators for flash radiography, dynamic materials experiments, and inertial-confinement fusion research.

\section{ACKNOWLEDGMENTS}

We wish to acknowledge many helpful conversations with Dr. M.E. Savage, Dr. J. J. Leckbee, Dr. B. Oliver, Dr. S. F. Glover, Dr. J. Alexander, and Dr. D. H. McDaniel along with Mr. Y. Molina, Mr. R. Chavez, Mr. R. McKee, Mr. E.F. White, and Mr. S. Tullar at Sandia National Laboratories as well as Mr. J. Ennis and Mr. R. Hartsock at General Atomics Corporation. We also wish to acknowledge helpful conversations with Dr. K. LeChien of the National Nuclear Security Administration. Finally, we are grateful to the members of the RITS-6, Hermes-III, and LTDR accelerator crews for providing help with many small components. Sandia is a multiprogram laboratory operated by Sandia Corporation, a Lockheed-Martin company, for the United States Department of Energy's National Nuclear Security Administration under Contract No. DA-AC04-94-AL85000.
[1] F. Lassale, A. Loyen, A. Georges, B. Roques, H. Calamy, C. Mangeant, J. F. Cambonie, S. Laspalles, D. Cadars, G. Rodriguez, J. M. Delchie, P. Combes, T. Chancone, and J. Saves, in Proceedings of the 2007 Particle Accelerator Conference, Albuquerque, New Mexico (IEEE, Albuquerque, New Mexico, 2007), pp. 217-220.

[2] A. A. Kim, A. N. Bastrikov, S. N. Volkov, V. G. Durankov, B. M. Kovalchuk, and V. A. Sinebryukhov, Proceedings of 14th IEEE Pulsed Power Conference, Dallas, TX, 2003 (IEEE, Piscataway, NJ, 2007), pp. 853-854.

[3] J. Leckbee, J. Maenchen, S. Portillo, S. Cordova, I. Molina, D. L. Johnson, A. A. Kim, R. Chavez, and D. Ziska, in Proceedings of the 15th IEEE Pulsed Power Conference, 2005 (IEEE, Piscataway, NJ, 2006), pp. 132-135.

[4] G. A. Mesyats, Pulsed Power (Kluwer Academic/Plenus Publishers, New York, 2005), pp. 264-265.

[5] J. J. Leckbee, J. E. Maenchen, D. L. Johnson, S. Portillo, D. E. Van DeValde, D. V. Rose, and B. V. Oliver, IEEE Trans. Plasma Sci. 34, 1888 (2006).

[6] A. A. Kim, A. N. Bastrikov, S. N. Volkov, V. G. Durakov, B. M. Kovalchuk, and V. A. Sinebryukhov, in Proceedings of the 13th International Symposium on High Current Electronics, Tonsk, Russia, 2004 (High Current Electronics Institute, Tomsk, Russia, 2004), pp. 141-144.

[7] M. G. Mazarakis et al., Phys. Rev. ST Accel. Beams 12, 050401 (2009).

[8] A. A. Kim et al., Phys. Rev. ST Accel. Beams 12, 050402 (2009).

[9] D. V. Rose et al., Phys. Rev. ST Accel. Beams 13, 090401 (2010).

[10] A. Kim et al., in Proceedings of the 2009 IEEE Pulsed Power Conference (IEEE Report No. CFP09PPC-DVD).

[11] J. R. Woodworth et al., Phys. Rev. ST Accel. Beams 13, 080401 (2010).

[12] Part number 40264-200SD; available from L3 Communications, Pulse Sciences Division, 4855 Ruffner St., San Diego, CA 92111.

[13] "Principles of Charged Particle Acceleration" by Dr. Stanley Humphries contains a good introduction to ferromagnetic toroidal cores. This book is available free, online, at http://www.fieldpoint.com/cpa.html.

[14] A. A. Kim et al., Phys. Rev. ST Accel. Beams 13, 070401 (2010).

[15] Metglas ${ }^{\circledR}$ Inc. is a subsidiary of Hitachi Metals America LTD and can be contacted at $800-581-7654$ or at http:// www.metglas.com.

[16] Luminol is available from PETRO-Canada, Inc.

[17] Circle Seal 500 series pressure-relief valves

[18] S. A. Slutz et al., Phys. Plasmas 17, 056303 (2010).

[19] D. B. Sinars et al., Phys. Rev. Lett. 105, 185001 (2010).

[20] A. A. Kim et al., Phys. Rev. ST Accel. Beams 13, 070401 (2010).

[21] J. J. Leckbee (private communication).

[22] YSI, Inc. Model 3417 conductivity probe, available at http://www.ysi.com.

[23] W. A. Stygar et al., Phys. Rev. ST Accel. Beams 10, 030401 (2007). 